\title{
Effectiveness Through Reasonableness Preliminary Steps to Pragma-Dialectical Effectiveness Research
}

\author{
Frans H. van Eemeren • Bart Garssen • Bert Meuffels
}

Published online: 4 October 2011

(C) The Author(s) 2011. This article is published with open access at Springerlink.com

\begin{abstract}
The introduction of the concept of strategic maneuvering into the pragma-dialectical theory makes it possible to formulate testable hypotheses regarding the persuasiveness of argumentative moves that are made in argumentative discourse. After summarizing the standard pragma-dialectical approach to argumentation, van Eemeren, Garssen, and Meuffels explain what the extension of the pragma-dialectical approach with strategic maneuvering involves and discuss the fallacies in terms of the extended pragma-dialectical approach as derailments of strategic maneuvering. Then they give an empirical interpretation of the extended pragma-dialectical model in which they report the testing of three hypotheses which formulate preliminary conditions for effectiveness research within the framework of the extended pragma-dialectical theory and the results of the tests they consecutively carried out.
\end{abstract}

Keywords Effectiveness - Persuasiveness - Pragma-dialectics - Reasonableness · Strategic maneuvering

\section{Introduction}

According to van Eemeren (2010), the participants in argumentative discourse are in the predicament of having to reach the results that are the most advantageous from their points of view while remaining within the boundaries of reasonableness. This is why they have to maneuver strategically to reconcile their pursuit of effectiveness with the maintenance of reasonableness (p. 40). In pragma-dialectical terms, this means that in their strategic maneuvering they try to be convincing by combining

F. H. van Eemeren · B. Garssen $(\bowtie) \cdot$ B. Meuffels

University of Amsterdam and ILIAS, Amsterdam, North Holland, The Netherlands

e-mail: B.J.Garssen@uva.nl 
artful rhetorical operating systematically with complying fully with the dialectical rules for critical discussion.

The introduction of the concept of strategic maneuvering into the pragmadialectical theory makes it possible to formulate testable hypotheses regarding the persuasiveness of argumentative moves that are made in argumentative discourse. Taking our departure from this observation, we have started a comprehensive research project under the title Pragma-Dialectical Effectiveness Research (for theoretical reasons which we will explain in this paper we consider it more appropriate to use the term effectiveness instead of persuasiveness). This project is aimed at determining methodically what kinds of argumentative moves can be effective in the process of convincing another party.

Before we can embark on the pragma-dialectical effectiveness research we have in mind, some preliminary questions need to be answered. First, we need to know whether ordinary arguers are indeed aware of their dialectical obligations. Second, we need to find out whether they do assume that the other party in the discussion is committed to the same kind of dialectical obligations. Third, we need to establish whether ordinary arguers prefer the participants in a discussion to be held accountable for being unreasonable when their discussion contributions violate the joint norms of reasonableness that are incorporated in the rules for critical discussion. Because our notion of effectiveness is not exactly the same as the notion of persuasiveness, fifth, as a last preliminary step to the start of our pragmadialectical effectiveness research, we need to clarify the conceptual and theoretical differences.

In this article, we explain in Sect. 2 first the quintessence of the standard pragmadialectical approach to argumentation. In Sect. 3, we sketch the pragma-dialectical treatment of the fallacies as violations of rules for critical discussion. In Sect. 4, we explain the fallacies in terms of the extended pragma-dialectical approach as derailments of strategic maneuvering. Next, we give in Sect. 5 an empirical interpretation of the extended pragma-dialectical model in which we discuss the testing of three hypotheses and the results of these tests. We end, in Sect. 6, with a conclusion in which we make clear what the implications are of the results of our preliminary research for our project Pragma-Dialectical Effectiveness Research.

\section{The Pragma-Dialectical Theory of Argumentation}

Scholars of argumentation are often drawn to studying argumentation by an interest in particular practices of argumentative discourse and improving their quality where this is called for. To be able to satisfy this interest, they have to combine an empirical orientation with a critical orientation towards argumentative discourse. This challenging combination can only be achieved if they not only examine argumentative discourse as a specimen of actual verbal communication and interaction but also measure its quality against normative standards of reasonableness. Pragma-dialecticians make it their business to clarify how the gap between the normative dimension and the descriptive dimension of argumentation can be systematically bridged, so that critical and empirical insights can be integrated. 
They tackle the complex problems that are at stake with the help of a comprehensive research program consisting of various interrelated components (Eemeren and van Grootendorst 2004, pp. 9-41). On the one hand, there is a philosophical component in which a philosophy of reasonableness must be developed and a theoretical component in which, starting from this ideal of reasonableness, a model for acceptable argumentation is to be designed. On the other hand, there is an empirical component in which argumentative reality as it is encountered in argumentative discourse must be investigated, qualitatively as well as quantitatively. Then, in the analytical component the normative and the descriptive dimensions must be systematically linked. Finally, in the practical component the problems must be identified that occur in particular argumentative practices and methods must be developed to solve these problems.

When developing the pragma-dialectical approach to argumentation, van Eemeren and Rob Grootendorst started from a conception of reasonableness that replaces so-called justificationism with a critical testing procedure (van Eemeren 1984, pp. 15-18). This critical and dialectical conception of reasonableness is associated with a "critical rationalist" philosophy of reasonableness which claims that, ultimately, we cannot be certain of anything and takes as its guiding principle the idea of critically testing all claims that are made to acceptability (van Eemeren and Grootendorst 1988). As Albert (1975) has emphasized, the critical rationalist conception of reasonableness is all embracing: it pertains to any subject that can be the object of a regulated discussion and covers - as we would like to have it - the discussion of descriptive as well as evaluative and prescriptive standpoints.

By implementing the critical rationalist view in the theoretical component of the research program we pursued the development of a model of critical discussion that gives substance to the idea of resolving differences of opinion on the merits by means of dialectically regulated critical exchanges in which the acceptability of the standpoints at issue is put to the test (van Eemeren and Grootendorst 1988, pp. 279-280). The outcome of the discussion between the protagonist and the antagonist depends on the critical questions asked by the antagonist and the adequacy of the protagonist's responses to these critical questions. The systematic account of the interaction that takes place between the speech acts performed by the protagonist to defend the standpoint and those performed by the antagonist to respond critically is characteristic of the "pragma-dialectical" resolution procedure we have designed, which combines a dialectical view of argumentative reasonableness with a pragmatic view of the verbal moves made in argumentative discourse as contextualized speech acts.

The model of a critical discussion we developed provides an overview of the argumentative moves that are pertinent to the completion of each of the discussion stages that furthers the process of resolving a difference of opinion on the merits in each particular stage. Analytically, in a critical discussion four stages can be distinguished that have to be completed in a constructive way in order to be able to resolve the difference of opinion on the merits. First, there is the "confrontation stage" in which the difference of opinion is externalized from the potential disagreement space. Next there is the "opening stage" in which the protagonist and the antagonist of a standpoint at issue in the difference of opinion determine their 
zone of agreement as far as common procedural and material starting points (or "concessions") are concerned. In the "argumentation stage" both parties try to establish whether, given the point of departure acknowledged by the parties, the protagonist's standpoint is tenable in the light of the antagonist's critical responses. Finally, in the "concluding stage," the result of the critical discussion is established.

In a critical discussion, the parties attempt to reach agreement about the acceptability of the standpoints at issue by finding out whether or not these standpoints are defensible against doubt or criticism. To be able to achieve this purpose, the dialectical procedure for conducting a critical discussion should not deal just with inference relations between premises and conclusions, but should cover all speech acts that play a part in testing the acceptability of standpoints. In pragma-dialectics, the notion of a critical discussion is therefore given shape in a model that specifies all the types of speech acts instrumental in any of the stages the resolution process has to pass. Because in actual argumentative discourse speech acts are often performed implicitly or indirectly, in practice, a great variety of speech acts may fulfill a constructive role in the process of resolving a difference of opinion on the merits (van Eemeren and Grootendorst 1984, 2004).

\section{The Pragma-Dialectical Treatment of the Fallacies}

In our view, the theorizing about fallacies has to start from a general and coherent perspective on argumentative discourse that provides a common rationale to the treatment of all fallacies. Because a theory of wrongs cannot be constructed independently of a theory of what is normatively correct, a theory of fallacies must be an integral part of a normative theory of argumentation that provides welldefined standards for judging argumentative discourse. The theoretical account of the fallacies should be systematically related to these standards in such a way that it is clear in all cases why the argumentative moves designated as fallacies are fallacious.

The simplest case of argumentation is that a speaker or writer advances a standpoint and acts as "protagonist" of that standpoint and a listener or reader expresses doubt with regard to the standpoint and acts as "antagonist." In the discussion that develops the two parties try to find out whether the protagonist's standpoint can withstand the antagonist's criticism. In this exchange an interaction takes place between the speech acts performed by the protagonist and those performed by the antagonist that is typical of what we call a "critical discussion." This interaction can, of course, only lead to the resolution of the difference of opinion if it proceeds in an adequate fashion. This requires a regulation of the interaction through rules for critical discussion specifying when exactly the performance of certain speech acts does or does not contribute to the resolution of the difference on the merits. ${ }^{1}$ The procedural rules proposed in pragma-dialectics

\footnotetext{
$\overline{1 \text { Because a procedure regulating }}$ the resolution of a difference must consist of a system of rules covering all speech acts that need to be carried out to resolve a difference of opinion, the procedure should relate to all four stages that are to be distinguished in a critical discussion.
} 
are claimed to be problem-valid because each of them contributes in a specific way to solving problems inherent in the process of resolving a difference of opinion. Their conventional validity is confirmed by systematic empirical research regarding their intersubjective acceptability (van Eemeren et al. 2009).

The rules for conducting a critical discussion must state all the norms pertinent to resolving a difference of opinion on the merits. The pragma-dialectical approach differentiates a functional variety of norms for judging fallaciousness. ${ }^{2}$ Rather than considering the fallacies as belonging to an unstructured list of nominal categories inherited from the past, or considering all fallacies to be violations of the same validity norm, different (combinations of) norms may be pertinent. ${ }^{3}$ Any move that is an infringement of any of these rules, whichever party performs it and at whatever stage in the discussion, is a possible threat to the resolution of a difference of opinion on the merits and must therefore-and in this particular sense-be regarded as fallacious. In this way the use of the term fallacy is systematically connected with the rules for critical discussion. In the pragma-dialectical approach a fallacy is thus a hindrance or impediment to resolving a difference of opinion on the merits and the specific nature of a particular fallacy depends on the way in which it interferes with the resolution process.

\section{Fallacies as Derailments of Strategic Maneuvering}

The pragma-dialectical theory of fallacies we have just sketched is, in our view, still not entirely satisfactory because it ignores the intriguing problem of the persuasiveness that fallacies may have-which is in fact why they deserve our attention. In the Logical Standard Definition of fallacies as "arguments that seem valid but are not valid," the persuasiveness of the fallacies was hinted at by the use of the word "seem," but since Hamblin (1970, p. 254) issued the verdict that including this qualification brings in an undesirable element of subjectivity, the treacherous character of the fallacies - the Latin word fallax means deceptive or deceitful-has been ignored and the search for its explanation abandoned. This means that fallacy theorists are no longer concerned with the question of how fallacies "work," that is, why they can be successful and why they can go so often unnoticed. Because of the nature of the problem, we think that the pragmadialectical theory of argumentation can only remedy this neglect if it is first enriched by insight from rhetoric.

The inclusion of rhetorical insight in the pragma-dialectical theory that van Eemeren and Peter Houtlosser have brought about is an effort to bridge the conceptual and cultural gap between dialectic and rhetoric that currently exists (van Eemeren and Houtlosser 2002; van Eemeren 2010). We started from the

\footnotetext{
${ }^{2}$ Each of the pragma-dialectical rules constitutes in principle a distinct norm for critical discussion.

3 A comparison shows that fallacies which were traditionally only nominally lumped together are now either shown to have something in common or clearly distinguished, whereas genuinely related fallacies that were separated are now brought together. In addition, the pragma-dialectical approach also enables the analysis of thus far unrecognized and unnamed "new" obstacles to resolving a difference of opinion on the merits.
} 
observation that in argumentative discourse, whether it takes place orally or in writing, it is not the sole aim of the arguers to conduct the discussion in a way that is considered reasonable, but also, and from a certain perspective even in the first place, to achieve the outcome that is from their point of view the best result. The arguers' rhetorical attempts to make things go in their way are, as it were, incorporated in their dialectical efforts to resolve the difference of opinion in accordance with proper standards for a critical discussion. This means in practice that at every stage of the resolution process the parties may be presumed to be at the same time out for the optimal rhetorical result at that point in the discussion and to hold to the dialectical objective of the discussion stage concerned. In their efforts to reconcile the simultaneous pursuit of these two aims, which may at times be at odds, the arguers make use of what we have termed strategic maneuvering. This strategic maneuvering is directed at diminishing the potential tension between jointly pursuing the "dialectical" aim of reasonableness and the "rhetorical" aim of effectiveness.

In argumentative discourse, strategic maneuvering manifests itself in the moves that are made in three aspects, which can be distinguished only analytically: "topical choice," "audience adaptation," and "presentational design." Topical choice refers to the specific selection that is made in a move from the topical potential-the set of dialectical options-available at a certain point of the discussion, audience adaptation involves framing a move in a perspective that agrees with the audience, and presentational design concerns the selection that the speaker or writer makes in a move from the existing repertoire of presentational devices. In their strategic maneuvering aimed at steering the argumentative discourse their own way without violating any critical standards in the process, both parties may be considered to be out to make the most convenient topical selection, to appeal in the strongest way to their audience, and to adopt the most effective presentation.

A clearer understanding of strategic maneuvering in argumentative discourse can be gained by examining how the rhetorical opportunities available in a dialectical situation are exploited in argumentative practice. Each of the four stages in the process of resolving a difference of opinion on the merits is characterized by having a specific dialectical objective. Because, as a matter of course, the parties want to realize these objectives to the best advantage of the position they have adopted, every dialectical objective has its rhetorical analogue. Because in each discussion stage the parties are out to achieve the dialectical results that serve their rhetorical purposes best, in each stage the rhetorical goals of the participants in the discourse will be dependent on-and therefore run parallel with-their dialectical goals. As a consequence, the specifications of the rhetorical aims that may be attributed to the participants must take place according to dialectical stage. This is the methodological reason why the study of strategic maneuvering that we propose boils down to a systematic integration of rhetorical insight in a dialectical framework of analysis. ${ }^{4}$

\footnotetext{
${ }^{4}$ What kind of advantages can be gained by strategic maneuvering depends on the particular stage one is in. In the confrontation stage, for instance, the dialectical objective is to achieve clarity concerning the issues that are at stake and the positions the parties assume. Each party's strategic maneuvering will therefore be aimed at directing the confrontation rhetorically towards a definition of the difference that
} 
Although in strategic maneuvering the pursuit of dialectical objectives can well go together with the realization of rhetorical aims, this does not automatically mean that in the end the two objectives will always be in perfect balance. If a party allows his commitment to a critical exchange of argumentative moves to be overruled by the aim of persuading the opponent, we say that the strategic maneuvering has got "derailed." Such derailments occur when a rule for critical discussion has been violated. In that case, trying to realize the rhetorical aim has gained the upper hand-at the expense of achieving the dialectical objective. Because derailments of strategic maneuvering always involve violating a rule for critical discussion, they are on a par with the wrong moves in argumentative discourse designated as fallacies. Viewed from this perspective, fallacies are derailments of strategic maneuvering that involve violations of critical discussion rules. ${ }^{5}$

Each mode of strategic maneuvering has, as it were, its own continuum of sound and fallacious acting and the boundaries between legitimate and illegitimate argumentative acting are not in all cases immediately crystal clear. ${ }^{6}$ More often than not, fallacy judgments are in the end contextual judgments that depend on the specific circumstances of situated argumentative acting. The criteria for determining whether or not a certain norm for critical discussion has been violated may be dependent on the institutional conventions of the "argumentative activity type" concerned, that is, on how argumentative discourse is disciplined in a particular sort of case. This does not automatically mean, of course, that there are no clear criteria for determining whether the strategic maneuvering has gone astray, but only that the specific shape these criteria take may vary to some extent from the one argumentative activity type to the other. Who or what counts as authoritative, for instance, may vary depending on the institutional requirements pertaining to the activity type concerned, so that an appeal to a certain kind of authority may be legitimate in the one case but not in the other. Referring to precedent, for example, can be a perfectly legitimate appeal to authority in a civil law case, but not, at least in some systems, in a criminal law case-let alone in a scientific discussion.

This account of the fallacies as derailments of strategic maneuvering explains why it may, as a matter of course, not be immediately apparent to all concerned that a fallacy has been committed, so that the fallacy can pass unnoticed. Each mode of

\footnotetext{
Footnote 4 continued

highlights precisely the issues this party wants to discuss. In the argumentation stage, where the standpoints at issue are challenged and defended, the dialectical objective is to test, starting from the point of departure established in the opening stage, the tenability of the standpoints that shaped the difference of opinion in the confrontation stage. Depending on the positions they have taken, the parties will maneuver strategically to engineer rhetorically the most convincing case-or the most effective attack, as the case may be.

5 This means in practice that the argumentative moves concerned are not in agreement with the relevant criteria for complying with a particular dialectical norm. These criteria are determined by the soundness conditions the argumentative moves have to fulfill to remain within the bounds of dialectical reasonableness in the argumentative context in which they are made and they may vary to some extent according to the argumentative activity type in which they occur.

6 The difference between legitimate manifestations of strategic maneuvering and manifestations that are fallacious is that in the latter case certain soundness conditions applying to that way of strategic maneuvering in a particular context have not been met.
} 
strategic maneuvering has, in principle, both sound and fallacious manifestations, so that it is more difficult to tell the fallacious manifestations apart from their sound counterparts than when the distinction involved two completely different types of animals, like when all legitimate moves would be cats and all fallacious moves were dogs. On top of that, it is fully in line with the presumption of reasonableness that a party that maneuvers strategically will normally be assumed to uphold a commitment to the rules of critical discussion (Jackson 1995), so that a presumption of reasonableness is conferred on every discussion move-and this presumption is also operative when the strategic maneuvering is fallacious.

Deviations from the rules for critical discussion may be hard to detect because none of the parties will be very keen on portraying themselves as unreasonable, so that it is to be expected that to realize a purpose that is potentially at odds with the objective of a particular discussion rule, rather than resorting to completely different means, they will stick to the usual dialectical means for achieving their objective and try to "stretch" the use of these means in such a way that they allow for the other purpose to be realized as well. Echoing the Logical Standard Definition of a fallacy, we can then say that the strategic maneuvering involved seems to be in agreement with the critical discussion rules, but is in fact not. The most tricky fallacies are violations of rules for critical discussion that manifest themselves in derailments of strategic maneuvering which can easily escape our attention because the derailed cases may be very similar to familiar instances of sound strategic maneuvering. ${ }^{7}$

\section{Empirical Interpretation of the Extended Pragma-Dialectical Model}

Extended pragma-dialectics provides the theoretical tools enabling the analyst to give a more refined, accurate and comprehensive analytic and evaluative account of "argumentative reality" than could be achieved by means of the purely dialectical tools of standard pragma-dialectics. In a reconstruction based on the extended pragma-dialectical theory, it is not only assumed that the arguers aim to resolve their dispute on the merits, but also that they are the same time intent on having their own standpoints accepted. With the help of the notion of strategic maneuvering it becomes possible to reconstruct argumentative discourse as it occurs in practice in such a way that not only the dialectical dimension pertaining to its reasonableness is taken into account, but also the rhetorical dimension pertaining to its effectiveness (van Eemeren 2010).

It should be clear however that extended pragma-dialectics does not provide an empirical model of the various ways in which in real-life argumentative discourse ordinary arguers try to achieve effective persuasion within the boundaries of

\footnotetext{
7 All the same, it is of course necessary to make the distinction. To mark the importance of the distinction between non-fallacious and fallacious strategic maneuvering most clearly, we do not use the same labels indiscriminately for the fallacious as well as the non-fallacious moves, as others do, but reserve the traditional—often Latinized—names of the fallacies, such as argumentum ad hominem, for the incorrect and fallacious cases only.
} 
dialectical rationality and reasonableness. ${ }^{8}$ The notion of strategic maneuvering is incorporated in a theoretical model with a normative character, which is not a tool for describing empirically the argumentative behavior of ordinary arguers and their intentional pursuit of persuasion goals. One of the consequences of the normative character of the model is that, strictly speaking, it cannot be put to a critical empirical test. After all, the model can neither be falsified nor be confirmed by means of empirical data. This does not mean, however, that viewed from an empirical point of view the model is useless. On the contrary: it is easy to see that the model operative in extended pragma-dialectics can very well function as a source for the derivation of theoretically motivated hypotheses about the argumentative behavior and persuasion goals of arguers in ordinary argumentative practice. And this is precisely the way in which we are going to use it in our present article.

If the notion of strategic maneuvering is given an empirical interpretation, three rather straightforward and plausible hypotheses can be derived from the theoretical model in which strategic maneuvering is incorporated. We will explain why this is the case and then formulate them.

If ordinary arguers would lack any knowledge of the boundaries of the norms of reasonableness as incorporated in the theoretical framework of pragma-dialectics, then there would be no reason for them to maneuver strategically in the sense inherent in the notion of strategic maneuvering- in that case, they could go all out for rhetorical effectiveness, pursuing only and exclusively their own personal persuasion aims. At a pre-theoretical level, they must generally know which contributions to the discussion are in accordance with the norms of reasonableness incorporated in the rules for critical discussion and are thus to be regarded as reasonable, and which contributions have to be considered as violations of these dialectical norms, so that these moves are to be regarded fallacious and thus unreasonable. Our first hypothesis therefore is that, at least to a certain extent, ordinary arguers are aware of their dialectical obligations. ${ }^{9}$

If ordinary arguers would in ordinary discussions not expect that their interlocutors apply similar norms and criteria for evaluating the reasonableness of the discussion contributions as they themselves do, again, there would be no reason for them to maneuver strategically, because without such jointly shared assumptions being in force (the protagonist expects... [...], the protagonist knows that the antagonist expects $[\ldots]$, etc.), there is no telling that the other party will indeed

\footnotetext{
${ }^{8}$ We follow O'Keefe's definition of persuasion: persuasion is "a successful intentional effort at influencing another's mental state through communication in a circumstance in which the persuadee has some measure of freedom" (2006, p. 5). For the differences between effectiveness and persuasiveness and our use of the terms rationality and reasonableness, see van Eemeren 2010, p. 39 and 29, respectively.

9 With words like 'know', 'knowledge' and 'aware' we don't mean that ordinary arguers have any conscious, articulated knowledge of the pragma-dialectical rules, let alone any theoretical sophistication (with the possible exception of the burden of proof rule, they certainly don't have, as we showed in Fallacies and Judgments of Reasonableness 2009, pp. 219-224). With these words and expressions we only mean that their discussion behavior (or assessment and judgment of discussion behavior) can be modeled as being sensitive to the pragma-dialectical rules and thus be couched in terms of these rules.
} 
recognize reasonable argumentative moves, which are in agreement with the dialectical norms, as reasonable and regard argumentative moves that are unmistakably fallacious according to dialectical standards unreasonable, so that it makes no sense having an argumentative exchange. ${ }^{10}$ Our second hypothesis therefore is that ordinary arguers assume that the other party in the discussion is committed to the same kind of dialectical obligations.

If ordinary arguers would not prefer to use the notion of 'reasonableness' primarily in a prescriptive sense that goes beyond just "descriptive" reasonableness in the sense of an empirically observable normativety, then there would be, again, no reason for them to maneuver strategically, because it would not be possible to issue any sanctions when the other party's makes argumentative moves that are not reasonable because they are not in agreement with the dialectical norms, so that having an argumentative exchange is of no consequence. Our third hypothesis therefore is that, assuming that their interlocutors prefer the same, ordinary arguers prefer participants in a discussion to be held accountable for being unreasonable when their discussion contributions violate commonly shared norms incorporated in the rules for critical discussion. ${ }^{11}$

\subsection{Hypothesis 1}

\subsubsection{Background}

Since 1995 we have collected a mass of empirical data that are relevant for testing the claim involved in the first hypothesis. We then started a comprehensive experimental research project titled Conceptions of Reasonableness, which was completed in 2008 (see van Eemeren et al. 2009). The aim of this project was to determine empirically which norms ordinary arguers use (or claim to use) when evaluating argumentative discourse, and to what extent these norms are in agreement with the critical theoretical norms of the pragma-dialectical theory of argumentation. Expressed differently: the aim of this ten-year project was to investigate and to test the conventional validity of the pragma-dialectical discussion rules: can it be expected that in actual discussion the rules are intersubjectively approved by the parties involved in a difference of opinion? The problem validity of the pragma-dialectical rules (are the rules instrumental in resolving a difference of opinion?) is primarily a theoretical issue. In contradistinction, the conventional validity of these rules can only be established by means of empirical research.

\footnotetext{
10 See the second part of Lewis's (1977, p. 42) definition of convention pertaining to shared expectations. Cf. van Eemeren and Grootendorst (1984, p. 60).

11 See the third part of Lewis' (1977, p. 42) definition of convention pertaining to the joint preference for complying with the shared expectations. Cf. van Eemeren and Grootendorst (1984, p. 60).
} 


\subsubsection{Method Hypothesis 1}

In the framework of the project Conceptions of Reasonableness, we carried out some 50 independent small-scale experiments, investigating the (un)reasonableness of 24 different types of fallacies. The setup of these experiments, the design of which we will report here, was in all cases the same: a repeated measurement design, combined with a multiple message design. That means that a variety of discussion fragments, short dialogues between two interlocutors A and B, were presented to the participants. (1) is an example of such a discussion fragment in which the abusive variant of the ad hominem fallacy is committed, (2) an example of the circumstantial variant, and (3) an example of the tu quoquevariant.

(1) (abusive variant; direct attack)

A: I think a Ford simply drives better; it shoots across the road.

B: How would you know? You don't know the first thing about cars.

(2) (circumstantial variant; indirect attack)

A: In my view, the best company for improving the dikes is Stelcom Ltd; they are the only contractor in the Netherlands that can handle such an enormous job.

B: Do you really think that we shall believe you? Surely, it is no coincidence that you recommend this company: It is owned by your father-in-law.

(3) (tu quoque-variant; you too variant)

A: I believe the way in which you processed your data statistically is not entirely correct; you should have expressed the figures in percentages.

B: You're not being serious! Your own statistics are not up to the mark either.

For baseline and comparison purposes, the participants also had to judge the (un)reasonableness of fragments in which no violation of a pragma-dialectical rule was committed:

(4) (no violation of the freedom rule)

A: I believe my scientific integrity to be impeccable; my research has always been honest and sound.

B: Do you really want us to believe you? You have already been caught twice tampering with your research results.

In all cases in the discussion fragments non-loaded topics were discussed, and in all cases paradigmatic, clear-cut cases of the fallacies were constructed. All fragments (in most experiments 48 in total) were put in a certain context. For instance, fragment (1) was presented in a domestic discussion context, fragment (2) in a political context, and fragment (3) and (4) in the context of a scientific debate. The participants were invariably asked to judge the reasonableness of the 
last contribution to the discussion, i.e. the contribution of $\mathrm{B}$ in the examples above. The participants had to indicate their judgment on a 7-point Likert scale, ranging from very unreasonable $(=1)$ to very reasonable $(=7)$.

\subsubsection{Results Hypothesis 1}

With regard to our first hypothesis our experimental research has shown (see Table $1^{12}$ ) that-with the notable exception of the logical variant of the argumentum ad consequentiam - the respondents made consistently a clear (i.e. statistically significant) distinction between the unreasonableness of discussion moves that, according to pragma-dialectical standards, involve a fallacy and those discussion moves that are not fallacious. In general, fallacious discussion moves are considered unreasonable and non-fallacious moves are considered reasonable. ${ }^{13}$

These results can be taken as a strong support for our first hypothesis: ordinary arguers are, at least to a certain extent, aware of what the dialectical obligations in an argumentative discussion entail. ${ }^{14}$

\subsection{Hypothesis 2}

The experiment we conducted to test the prediction involved in our second hypothesis derives from the extended model incorporating strategic maneuvering and pertains to the reciprocal social expectations of discussion parties regarding the commitment to dialectical discussion rules. The prediction is that ordinary arguers expect that the other party in the discussion is committed to the same kind of dialectical obligations as they themselves are. As for testing this second prediction (and, by the way, also the third prediction), we will make use of the empirical results obtained in the project Conceptions of Reasonableness.

\footnotetext{
12 Table 1 in which an overview is given of the empirical results of the project Conceptions of Reasonableness, is originally coming from Fallacies and Judgments of Reasonableness (i.e. Table 9.6 on page 223).

13 With the exception of the logical variant of the ad consequentiam fallacy, all differences in reasonableness between a particular fallacy and its non-fallacious counterpart are statistically significant-ordinary arguers not very often regard the reductio ad absurdum as a type of sound argumentation, just as they hardly see that the fallacy that copies this sound argumentation (namely the logical variant of the argumentum ad consequentiam) is an obvious fallacy. In some cases in Table 1 no effect size is reported-in those cases ES could not be computed, due to the specific characteristics of the chosen design. Moreover, from the data presented in Table 1 (and equally in Table 2) one may not infer that fallacies such as the $t u$ quoque-variant are regarded as reasonable moves. In Table 1 we abstracted from the specific discussion context in which the fallacies were offered to the participants, but in a scientific discussion context the tu quoque fallacy is invariably judged as an unreasonable move.

14 Notice that there is an enormous range in the judged unreasonableness of the various fallacies: the physical variant of the argumentum ad baculum, for example, is regarded as an absolute unreasonable move, while the tu quoque variant of the ad hominem fallacy tends to be considered as a reasonable move (provided we abstract from the specific discussion contexts in which this fallacy was presented). Such data make sense: threatening the other party in the discussion with brute physical violence is the example par excellence of irrational, unreasonable behavior, while committing a tu quoque fallacy has at least in some discussion contexts the appearance of being reasonable. Serious participants in a conversation may be expected to show some consistency between their (past and present) words and deeds.
} 
Table 1 Overview of average reasonableness score for fallacious discussion contributions and the nonfallacious counterparts; effect size (ES) for the difference between the (un)reasonableness of fallacious and non-fallacious discussion contributions, per argumentation stage

\begin{tabular}{|c|c|c|c|}
\hline & Violation & No violation & ES \\
\hline \multicolumn{4}{|l|}{ Violations of the freedom rule: confrontation stage } \\
\hline 1. Argumentum ad hominem (abusive variant) & 2.91 & 5.29 & 0.47 \\
\hline 2. Argumentum ad hominem (circumstantial variant) & 3.89 & 5.29 & 0.21 \\
\hline 3. Argumentum ad hominem (tu quoque variant) & 4.45 & 5.29 & 0.14 \\
\hline 4. Argumentum ad baculum (physical variant) & 2.04 & 5.64 & 0.57 \\
\hline 5. Argumentum ad baculum (non-physical variant) & 2.91 & 5.64 & \\
\hline 6. Argumentum ad baculum (direct variant) & 1.86 & 5.41 & 0.29 \\
\hline 7. Argumentum ad baculum (indirect variant) & 3.72 & 5.41 & \\
\hline 8. Argumentum ad misericordiam & 3.86 & 5.06 & 0.13 \\
\hline 9. Fallacy of declaring a standpoint taboo & 2.79 & 5.14 & 0.46 \\
\hline 10. Fallacy of declaring a standpoint sacrosanct & 2.68 & 5.67 & 0.52 \\
\hline \multicolumn{4}{|l|}{ Violations of the burden of proof rule: opening stage } \\
\hline 11. Fallacy of shifting the burden of proof (non-mixed dispute) & 2.37 & 4.51 & 0.36 \\
\hline \multicolumn{4}{|l|}{ 12. Fallacy of evading the burden of proof (non-mixed dispute) } \\
\hline Presenting standpoint as self-evident & 3.04 & 4.68 & 0.24 \\
\hline \multicolumn{4}{|l|}{ 13. Fallacy of evading the burden of proof (non-mixed dispute) } \\
\hline \multicolumn{4}{|l|}{ Giving personal guarantee of correctness of standpoint } \\
\hline By means of a commissive & 3.29 & 5.18 & 0.33 \\
\hline By means of a directive & 2.77 & 5.14 & 0.45 \\
\hline \multicolumn{4}{|l|}{ 14. Fallacy of evading the burden of proof (non-mixed dispute) } \\
\hline Immunizing standpoint against criticism & 2.68 & 4.76 & \\
\hline \multicolumn{4}{|l|}{ 15. Fallacy of evading the burden of proof (mixed dispute) } \\
\hline Standpoint without presumptive status & 2.72 & 5.68 & 0.63 \\
\hline Standpoint with presumptive status (truths) & 3.45 & 5.68 & 0.41 \\
\hline Standpoint with presumptive status (changes) & 3.48 & 5.68 & 0.45 \\
\hline \multicolumn{4}{|l|}{ Violations of the argumentation scheme rule: argumentation stage } \\
\hline \multicolumn{4}{|l|}{ 16. Argumentum ad consequentiam } \\
\hline Logical variant & 3.92 & 4.39 & 0.00 \\
\hline Pragmatic variant & 2.96 & 5.03 & 0.37 \\
\hline 17. Argumentum ad populum & 2.77 & 5.88 & 0.40 \\
\hline 18. Slippery slope & 3.31 & 5.31 & 0.25 \\
\hline 19. False analogy & 3.14 & 4.74 & 0.29 \\
\hline \multicolumn{4}{|l|}{ Violation of the rule for the concluding stage: concluding stage } \\
\hline 20. Argumentum ad ignorantiam & 2.56 & 5.56 & 0.50 \\
\hline
\end{tabular}

$1=$ very unreasonable; $4=$ neither unreasonable, nor reasonable; $7=$ very reasonable

In the project Conceptions of Reasonableness the three variants of the ad hominem-fallacy ('direct attack', 'circumstantial', tu quoque) are investigated frequently, not only in the Netherlands but also in other countries (see Table 2). 
Table 2 Average reasonableness score for three types of ad hominem-fallacy (direct attack (=dir), indirect attack (=ind), tu quoque variant (=tu)) and for non-fallacious reasonable argumentation, per replication (standard deviation: between brackets)

\begin{tabular}{lllll}
\hline & dir & ind & tu & Reasonable \\
\hline Original investigation & $2.91(.64)$ & $3.89(.57)$ & $4.45(.60)$ & $5.29(.64)$ \\
Replication 1 & $2.99(.76)$ & $3.47(.94)$ & $3.82(.88)$ & $5.26(.72)$ \\
Replication 2 & $3.08(.66)$ & $3.82(.92)$ & $4.15(.61)$ & $5.03(.65)$ \\
Replication 3 & $3.38(.87)$ & $4.21(.78)$ & $4.54(.67)$ & $5.09(.67)$ \\
Replication 4 (UK) & $3.32(.64)$ & $4.13(.61)$ & $4.54(.46)$ & $5.24(.48)$ \\
Replication 5 (Germany) & $2.99(.61)$ & $3.52(.66)$ & $3.93(.63)$ & $4.88(.42)$ \\
Replication 6 (Spain) & $3.51(.87)$ & $4.23(.70)$ & $4.49(.73)$ & $4.93(.65)$ \\
Replication 7 (Spain) & $3.01(1.12)$ & $3.61(.75)$ & $3.99(.78)$ & $4.97(.86)$ \\
Replication 8 (Indonesia) & $3.21(.78)$ & $3.75(.99)$ & $4.53(.83)$ & $5.10(.56)$ \\
\hline
\end{tabular}

$1=$ very unreasonable; $4=$ neither unreasonable, nor reasonable; $7=$ very reasonable

As a consequence, we have now insights into (1) the stability of the reasonableness data for the three types of fallacy and for the non-fallacious discussion contributions, (2) the ordinal reasonableness relations of the three types of fallacy, and (3) the absolute reasonableness assessments of the three types of fallacy. In our investigation of prediction 2 we exposed our respondents again to instantiations of the three types of ad hominem fallacy and instantiations of nonfallacious moves. We requested them to rate the (un)reasonableness of these discussion fragments (i.e. the last contribution) according to their own insights and judgment. In addition, they had to rate similar fallacious and non-fallacious fragments, but with the instruction to indicate how reasonable or unreasonable they think and expect that relevant others would judge these fragments. Prediction 2 can be considered to be confirmed if the three stable patterns of Table 2, ((1) stability of the reasonableness data for the three types of fallacy in comparison with the judged reasonableness of non-fallacious argumentation, (2) stability of the ordinal reasonableness relations of the three types of fallacy, and (3) stability of the absolute reasonableness assessments of the three types of fallacy), show up again, not only in the condition in which the participants have to rate the fragments according to their own insight but equally well in the condition in which they have to make an estimation of the judgment of relevant others. A statistical significant interaction between 'condition' and 'type of fallacy' would been disastrous for the confirmation of prediction 2 .

\subsubsection{Method Hypothesis 2}

In order to test hypothesis 2, 48 discussion fragments were constructed: short dialogues between two discussants (called A and B) in which the antagonist B violated 36 times the pragma-dialectical rule for the confrontation stage by means of one of the three variants of the argumentum ad hominem. In 12 discussion fragments no discussion rule was violated; in those fragments B adduced only non-fallacious, reasonable argumentation. 
Two versions were constructed: version 'Self' and version 'Other', both consisting of 24 discussion fragments; the fragments in each version were randomly drawn from the whole set of 48 fragments and subsequently quasi-randomly assigned to one of the two versions, such that both versions contained precisely the same number of instantiations of the same type of fallacy. Consequently, both in the version Self and in the version Other the direct attack, the indirect attack and the tu quoque-variant are each represented by 6 instantiations. The design in this experiment can thus characteristically be regarded as a multiple message design (examples of concrete messages presented to the participants are shown in 5.1.2).

Fifty-six pupils of the fourth and fifth year of secondary school (most of them 16 and 17 years old respectively) participated in the experiment; none of them had ever had any specific argumentation teaching. After each discussion fragment in the version Self the question that is asked is "How reasonable or unreasonable do you (yourself) think B's reaction is?", and in the version Other the question that is asked is "How reasonable or unreasonable do you think relevant others would judge B's reaction?" (relevant others were in the instruction described as friends or relatives). In both versions they could indicate their judgment on a 7-point scale, ranging from 1 'very unreasonable' $(=1)$ to 'very reasonable' $(=7)$. The order of presentation of the two versions was randomized over the subjects; half of the participants had first to fill in the version Self and subsequently the version Other, the other half of the participants received the reversed order (as there were no statistical significant differences between the two orders, we will abstract from this variable). As all the participants were exposed to all levels of both the independent variable 'version' and the independent variable 'fallacy/no fallacy', the chosen design can also be described as a repeated measurement design.

\subsubsection{Results Hypothesis 2}

The data in Table 3 were analyzed by means of a multivariate analysis of variance ('mixed model' approach for repeated measurements, with 'subject' and 'instantiation' as random factors and the variables 'version' and 'type of fallacy' as fixed factors; the random factor 'instantiation' is nested within the interaction of the fixed factors 'version' and 'type of fallacy', whereas the random factor 'subject' is fully crossed with the random factor 'instantiation' and the fixed factors 'version and 'type of fallacy'; the statistical consequence of this rather complicated design is

Table 3 Average reasonableness score for three types of ad hominem-fallacy and for non-fallacious reasonable argumentation, per version $(N=56)$

\begin{tabular}{lllll}
\hline & dir & ind & tu & Reasonable \\
\hline Version & & & & \\
Self & $2.90(.83)$ & $4.32(.68)$ & $4.65(.59)$ & $4.77(.69)$ \\
Other & $3.28(.80)$ & $3.95(.76)$ & $4.27(.74)$ & $4.94(.72)$ \\
& $3.09(.72)$ & $4.13(.59)$ & $4.46(.51)$ & $4.86(.61)$ \\
\hline
\end{tabular}

$1=$ very unreasonable; $4=$ neither unreasonable, nor reasonable; $7=$ very reasonable 
that-instead of ordinary F-ratio's — quasi F-ratio's have to be computed, while the degrees of freedom have to be approximated (see Clark 1973).

From the data in Table 3 it is evident that the well known ordinal pattern in reasonableness relations between the three types of ad hominem fallacies crop up again in this experiment, regardless of the type of condition (version). No matter whether the participants have to base their reasonableness ratings on their own judgment or whether they have to estimate the verdict regarding the unreasonableness of the three variants of the ad hominem fallacy of relevant others, the direct attack is invariably judged as the most unreasonable move, next the indirect attack and subsequently the tu quoque-variant. And precisely as was the case in the investigations presented in Table 2, again the $t u$ quoque-variant tends to be considered as a reasonable discussion move.

So far as the differences in reasonableness between non-fallacious reasonable argumentation on the one side and fallacious argumentation on the other side are concerned, there are no statistically significant differences between the version Self and the version Other: In both conditions reasonable argumentation is regarded (in an absolute sense) as reasonable, while in both conditions the direct attack and the indirect attack are considered as significantly less reasonable than non-fallacious argumentation (contrast direct attack vs. reasonable argumentation $\mathrm{F}(1,42)=$ 84.46; $p<.001 ; \mathrm{ES}=0.31$; contrast indirect attack vs. reasonable argumentation $\mathrm{F}(1,28)=12.51 ; p<.001 ; \mathrm{ES}=0.07)$. However, both in the condition Self and in the condition Other our subjects do not discriminate between the (un)reasonableness of the tu quoque-variant and the (un)reasonableness of reasonable argumentation: $\mathrm{F}(1,23)=2.60$; n.s.).

At least as important for the confirmation of prediction 2 is our finding that there is no statististical significant (main) effect of the independent variable 'condition' in case of the three relevant contrasts between (1) the direct attack and reasonable argumentation: $F(1,32)=3.81$; n.s., (2) the indirect attack and reasonable argumentation: $\mathrm{F}(1,25)=0.35$; n.s., and the tu quoque-variant and reasonable argumentation: $\mathrm{F}(1,25)=0.24$; n.s., nor a statistically significant interaction between the independent variables 'condition' and 'fallacy/no fallacy' (direct attack: $\mathrm{F}(1,25)=0.41$; n.s.; indirect attack: $\mathrm{F}(1,27)=1.72$; n.s.; tu quoque-variant: $\mathrm{F}(1,23)=1.17$; n.s. $)$.

All these results point in the same direction: ordinary arguers expect others to judge the (un)reasonableness of fallacious and non-fallacious discussion contributions in a similar way as they themselves do.

\subsection{Hypothesis 3}

\subsubsection{Method Hypothesis 3}

Prediction 3, involved in our third hypothesis, was that ordinary arguers will prefer-and assume that their interlocutors will prefer-that discussants who violate the commonly shared rules for critical discussion are not left alone but will be considered unreasonable and, if need be, reproached for being unreasonable. Consequently, ordinary arguers will not only use the notion of reasonableness in a 
merely "descriptive" normative sense, but also and primarily in a prescriptive sense. Building on our consistent findings in the project Conceptions of Reasonableness, in testing the third prediction we presented again the three variants of the ad hominem fallacy to the respondents, but this time the contributions in the discussion fragments did not have to be judged on their reasonableness. Instead, they had to be rated according to the extent that in these contributions the antagonist is violating a norm.

Fifty-nine subjects (18-19 years old pupils) participated in this experiment. Similar discussion fragments were presented to them as in the previous experiment. In 12 of the 48 fragments the fallacy of the direct attack was committed, in 12 fragments the indirect attack, in 12 fragments the tu quoque-variant and in the remaining 12 fragments reasonable argumentation was used. This time the reaction of antagonist $\mathrm{B}$ had to be judged on a 7-point, scale ranging from 'absolutely violating a norm' $(=1)$ to 'not at all norm-violating' (=7). The design of this experiment is the same as in the previous experiment: a repeated measurement design, combined with a multiple message design.

\subsubsection{Results Hypothesis 3}

As is evident from Table 4, the familiar patterns are again present:

The direct attack is judged as the most norm-violating move, next the indirect attack, and finally the tu quoque variant. As expected, the non-fallacious contributions to the discussion are rated as moves that can be regarded as nonnorm-violating. Each of the three ad hominem fallacies is judged in a statistically significant sense as more rule violating compared with non-fallacious reasonable argumentation. Each of the three ad hominem fallacies is judged in a statistically significant sense as more rule violating compared with non-fallacious reasonable argumentation. This holds even in the case of the tu quoque variant (direct attack: $\mathrm{F}(1,72)=65.73 ; p<.000 ; \mathrm{ES}=0.27$; indirect attack: $\mathrm{F}(1,58)=31.80 ; p<.000$; $\mathrm{ES}=0.13$; t q quoque variant: $\mathrm{F}(1,28)=6.03$; $p<.02$; $\mathrm{ES}=0.04)$. Nor surprisingly in light of the data in Table 2, there are big differences between the three types of fallacies regarding the extent to which they are regarded as norm-violating $(\mathrm{F}(2,57)=15.03 ; p<.000 ; \mathrm{ES}=0.11)$. According to the judgment of our respondents, in case of the direct attack the norms are much more violated than in the case of the other two types of fallacy $(\mathrm{F}(1,57)=23.41 ; p<.001)$. In turn, the indirect attack is considered more norm-violating than the move involving the $t u$ quoque variant $(\mathrm{F}(1,57)=5.92 ; p<.02)$.

Table 4 Average scores for the extent of norm violation for three types of ad hominem fallacy and for non-fallacious reasonable argumentation $(N=59)$

\begin{tabular}{llll}
\hline $\operatorname{dir}$ & ind & tu & Reasonable \\
\hline $2.97(1.11)$ & $3.64(1.04)$ & $4.18(.72)$ & $4.76(.88)$ \\
\hline
\end{tabular}

$1=$ absolutely violating a norm; $7=$ not at all norm-violating 
In sum, discussion moves that are considered unreasonable by our respondents (moves which are according to the pragma-dialectical standards also unreasonable in a theoretical sense) are judged to be norm-violating, while moves that our respondents judge reasonable (moves which are also reasonable in a theoretical sense) are considered as not norm-violating.

\section{Conclusions and Implications for Pragma-Dialectical Effectiveness Research}

As we have shown, bridging the paradigmatic division between the dialectical perspective and the rhetorical perspective on argumentative discourse with the help of the theoretical notion of strategic maneuvering, as proposed in the extended pragma-dialectical theory of argumentation, makes it possible to integrate rhetorical insights into a dialectical framework of analysis and to examine empirically the relationship between the arguers' aiming for rhetorical effectiveness and complying with dialectical standards of reasonableness. If the theoretical model underlying this analytic framework is interpreted empirically, three vital claims can be derived, which experimental research has shown to be strongly supported by pertinent empirical data.

First, ordinary arguers are to a certain extent aware of what we call their dialectical obligations because they generally know which contributions to a discussion are to be considered reasonable and which contributions are to be considered unreasonable, and therefore fallacious. The standards they use in giving their judgments, agree strongly with the norms incorporated in the pragmadialectical rules for critical discussion. Second, ordinary arguers assume that the other party in the discussion will be committed to the same kind of dialectical obligations as they themselves are. Third, ordinary arguers prefer-and assume that their interlocutors prefer-that contributions to the discussion that do not comply with supposedly commonly shared standard for critical discussion will be regarded as unreasonable and that interlocutors who offend the standards for critical discussion can be held accountable for being unreasonable.

What do these results mean for our perception of the relationship between reasonable argumentation and persuasiveness? All three hypotheses that we have tested empirically constitute preparatory theoretical steps for determining this relationship more closely. ${ }^{15}$ If, unlike we hypothesized in our first hypothesis, arguers were not aware of any committing standards of reasonableness, there could not be any rational relationship between reasonableness and persuasiveness in the sense that becoming persuaded is based on the reasonableness of the argumentation that is put forward. ${ }^{16}$ And the fact that arguers are committed to standards of reasonableness that are equivalent with the pragma-dialectical standards makes it

\footnotetext{
15 The three hypotheses are in fact closely connected with the theoretical views on the relationship between argumentation and persuasiveness in the sense of convincingness expounded in van Eemeren and Grootendorst (1984).

${ }^{16}$ Cf. van Eemeren and Grootendorst's (1984, pp. 63-74) analysis of rational perlocutionary effects.
} 
possible to substantiate what reasonableness means to them. If, unlike we hypothesized in our second hypothesis, arguers did not expect that the party addressed has in principle the same (or equivalent) standards of reasonableness as they have, their appealing to the other party's standards of reasonableness by putting forward argumentation would be pointless. And the fact that they prove to assume that there are shared standards of reasonableness makes it possible to connect the standards of reasonableness arguers have with their aiming for effectiveness with the other party. If, finally, unlike we hypothesized in our third hypothesis, arguers did not prefer that the prevailing standards are put into effect, their argumentative efforts would be pointless in the sense that they would not lead to any consequences. And the fact that arguers prove to give reasonableness a prescriptive meaning, and expect their interlocutors to do the same, makes it possible to interpret the connection between reasonableness and persuasiveness in such a way that, in principle, reasonableness may be expected to induce persuasiveness in others, even if in communicative practice, or in certain kinds of communicative practices, reasonableness would not be the only factor, and even not the biggest factor, leading to bringing about persuasion. ${ }^{17}$ Correlatively: if reasonableness in argumentative contributions of arguers is deficient or totally lacking, persuasiveness won't be achieved.

Against this background it makes sense for argumentation theorists to pay attention to the relationship between reasonableness and persuasiveness and to examine the connection between the two in their empirical research. In our view, however, this empirical research should differ from the prevailing persuasion research. Presently, persuasion researchers are predominantly oriented towards social and cognitive psychology and connect persuasiveness with the more general attitudes individuals have rather than with the successful defense of specific standpoints in argumentative discourse. Persuasion effect research seems to concentrate in the first place on showing empirically the influence that isolated factors, such as presenting a view explicitly or making use of a rhetorical question, can have on the persuasiveness of the message. As it is commonly practiced, persuasion research in general and persuasion effect research in particular is by no means focused on the effectiveness of argumentative appeals to reasonableness in the dialogical situations of argumentative discourse. Therefore, as an alternative, we would like to propose to complement (not to substitute) this type of research with theoretically motivated empirical effectiveness research concentrating on the strategic maneuvering involved in making certain argumentative moves at a particular stage of the process of resolving a difference of opinion on the merits, taking all three aspects of strategic maneuvering into account.

Our preference for 'effectiveness' research rather than 'persuasiveness' research is not so much motivated by the fact that the term effectiveness lacks the psychological connotations of the term persuasiveness and the irrational overtones that go with the latter, as by the fact that the term effectiveness is not exclusively applicable to argumentative moves made in the argumentation stage (as at least the term persuasiveness is), but also to argumentative moves made in the other

\footnotetext{
17 According to Wittgenstein, "at the end of reasons comes persuasion" (cited in Fogelin 2005, p. 9).
} 
dialectical discussion stages (which are not aimed directly at gaining acceptance of a standpoint). In accordance with an earlier proposal made by van Eemeren and Grootendorst, 'effectiveness' is in this empirical research to be defined as realizing the 'inherent' interactional (or perlocutionary) effect that is conventionally aimed for by performing the speech acts by which the argumentative moves concerned are made (van Eemeren 1984, pp. 24-29). In this way, pragma-dialectical effectiveness research will concentrate only on intentional and externalizable effects regarding the addressee's dialectical commitments which are achieved by using reasonable means and depend on the outcome of rational considerations on the part of the addressee based on an understanding of the functional rationale of the argumentative moves concerned. This empirical effectiveness research starts from the notion of strategic maneuvering and the theoretical framework in which this notion is embedded, takes account of all three mutually interdependent aspects inherent in strategic maneuvering and covers all stages of the dialectical process. ${ }^{18}$

Acknowledgments This paper is based on our joint contribution to the $7^{\text {th }}$ ISSA Conference in Amsterdam (van Eemeren 2011) and van Eemeren's contribution to the colloquium "Persuasion et Argumentation" in Paris (September 7, 2010).

Open Access This article is distributed under the terms of the Creative Commons Attribution Noncommercial License which permits any noncommercial use, distribution, and reproduction in any medium, provided the original author(s) and source are credited.

\section{References}

Albert, H. 1975. Traktat über kritische Vernunft, 3rd ed. Tubingen: Mohr.

Clark, H.H. 1973. The language-as-fixed-effect-fallacy. Journal of Verbal Learning and Verbal Behavior 12: 335-359.

Fogelin, R.J. 2005. The logic of deep disagreements. Informal Logic 25: 3-11.

Hamblin, C.L. 1970. Fallacies. London: Methuen. Reprinted Newport News, Va: Vale Press.

Jackson, S. 1995. Fallacies and heuristics. In Analysis and evaluation. Proceedings of the third ISSA conference on argumentation, ed. F.H. van Eemeren, R. Grootendorst, J.A. Blair, and C.A. Willard, vol. 2, 257-269. Amsterdam: Sic Sat.

Lewis, D.K. 1977. Convention: A philosophical study, 3rd ed. Cambridge, Mass: Harvard University Press. (1st ed. 1969).

O'Keefe, D. 2006. Pragma-dialectics and persuasion effect research. In Considering pragma-dialectics. A festschrift for Frans van Eemeren on the occasion of his 60th birthday, ed. P. Houtlosser and M.A. van Rees, 235-243. Mahwah: Lawrence Erlbaum.

van Eemeren, F.H. 2010. Strategic maneuvering in argumentative discourse. Extending the pragmadialectical theory of argumentation. Amsterdam-Philadelphia: John Benjamins.

van Eemeren, F.H., B. Garssen, and B. Meuffels. 2009. Fallacies and judgments of reasonableness. Empirical research concerning the pragma-dialectical discussion rules. Dordrecht: Springer.

van Eemeren, F.H., Garssen, B.J., and Meuffels, B. 2011. The extended pragma-dialectical argumentation theory empirically interpreted. In Proceedings of the 7th conference of the international society for

\footnotetext{
18 We think, in fact, that it is not too bold to conclude that the empirical results reported in this article lend more credibility to the general idea that reasonableness plays an important part in rhetorical persuasiveness, even to the extent that, in principle, reasonableness may be considered a necessary condition for the rational version of persuasiveness that van Eemeren and Grootendorst dubbed convincingness (van Eemeren and Grootendorst 1984, p. 48).
} 
the study of argumentation, ed. F.H. van Eemeren, B.J. Garssen, D. Godden, and G. Mitchell. Amsterdam: Sic Sat, CD Rom.

van Eemeren, F.H., and Grootendorst, R. 1984. Speech acts in argumentative discussions: A theoretical model for the analysis of discussions directed towards solving conflicts of opinion. Berlin/Dordrecht: De Gruyter/Foris.

van Eemeren, F.H., and R. Grootendorst. 1988. Rationale for a pragma-dialectical perspective. Argumentation 2(2): 271-291.

van Eemeren, F.H., and R. Grootendorst. 2004. A systematic theory of argumentation: The pragmadialectical approach. Cambridge: Cambridge University Press.

van Eemeren, F.H., and P. Houtlosser. 2002. Strategic maneuvering: Maintaining a delicate balance. In Dialectic and rhetoric: The warp and woof of argumentation analysis, ed. F.H. van Eemeren and P. Houtlosser, 131-159. Dordrecht: Kluwer. 